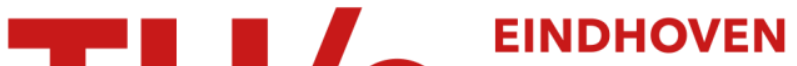 UNIVERSITY OF TECHNOLOGY
}

\section{Circumventing LoS blocking in beam-steered optical wireless systems with real-time tracking and handover}

Citation for published version (APA):

Mekonnen, K. A., Pham, N., Huijskens, F. M., Tangdiongga, E., Mefleh, A., \& Koonen, A. M. J. (2020).

Circumventing LoS blocking in beam-steered optical wireless systems with real-time tracking and handover. In Proceedings of the The Optical Networking and Communication Conference \& Exhibition (OFC2020) [9083166] Optical Society of America (OSA). https://ieeexplore.ieee.org/document/9083166

Document status and date:

Published: $13 / 05 / 2020$

\section{Document Version:}

Accepted manuscript including changes made at the peer-review stage

\section{Please check the document version of this publication:}

- A submitted manuscript is the version of the article upon submission and before peer-review. There can be important differences between the submitted version and the official published version of record. People interested in the research are advised to contact the author for the final version of the publication, or visit the $\mathrm{DOI}$ to the publisher's website.

- The final author version and the galley proof are versions of the publication after peer review.

- The final published version features the final layout of the paper including the volume, issue and page numbers.

Link to publication

\section{General rights}

Copyright and moral rights for the publications made accessible in the public portal are retained by the authors and/or other copyright owners and it is a condition of accessing publications that users recognise and abide by the legal requirements associated with these rights.

- Users may download and print one copy of any publication from the public portal for the purpose of private study or research.

- You may not further distribute the material or use it for any profit-making activity or commercial gain

- You may freely distribute the URL identifying the publication in the public portal.

If the publication is distributed under the terms of Article $25 \mathrm{fa}$ of the Dutch Copyright Act, indicated by the "Taverne" license above, please follow below link for the End User Agreement:

www.tue.nl/taverne

Take down policy

If you believe that this document breaches copyright please contact us at:

openaccess@tue.nl

providing details and we will investigate your claim. 


\title{
Circumventing LoS Blocking in Beam-Steered Optical- Wireless Systems with Real-time Tracking and Handover
}

\author{
Ketema Mekonnen $^{1 *}$, Quan Pham ${ }^{1}$, Frans Huijskens ${ }^{1}$, Eduward Tangdiongga ${ }^{1}$, Ali Mefleh ${ }^{2}$, Ton Koonen ${ }^{1}$ \\ ${ }^{\prime}$ Institute for Photonic Integration, Eindhoven University of Technology, Den Dolech 2, 5612AZ Eindhoven, The Netherlands \\ ${ }^{2}$ KPN, CTO, Technology Roadmap \& Architecture, Maanplein 55, The Hague, The Netherlands \\ k.a.mekonnen@tue.nl
}

\begin{abstract}
This paper demonstrates a real-time user tracking and handover mechanism for indoor ultrahigh-speed beam-steered optical-wireless systems implementing a low-cost camera. This allows us to tackle LoS blocking by switching to a secondary beam-steering device automatically.

OCIS codes: (060.2605) Free-space optical communication; (050.0050) Diffraction and gratings; (100.2000) Digital image processing; (100.4999) Pattern recognition, target tracking
\end{abstract}

\section{Introduction}

Optical-wireless communication (OWC) has been proven to be a very promising alternative to radio access techniques such as WiFi and millimeter wave to combat the looming capacity crunch and interference problems in the radio frequency regions due to the ever growing demand for higher speed wireless services. The visible and infrared regions have been under intense investigation [1,2]. Visible light communication (VLC) uses light emitting diodes (LEDs), which are optimized for illumination, to piggy-back data transmission. Therefore, due to limited modulation bandwidth of LEDs and their large beam footprint, $10 \mathrm{~Gb} / \mathrm{s}$ and higher transmission speeds per user are beyond the capability of VLC. By using steerable narrow infrared beams, each user can get an unshared wireless channel with larger link power budget, enhanced privacy, and better energy efficiency [3]. In particular, IR wavelengths beyond $1400 \mathrm{~nm}$, which allow beam powers up to $10 \mathrm{~mW}$ according to eye safety standards [4], also enable us to deploy the mature and widely available high-speed components in conventional optical fiber communication systems.

However, most of the research on narrow beam based OWC so far focused on establishing the point-to-point communication link, without giving much emphasis on user mobility. In order to appropriately direct the narrow IR beams to moving users accurate localization, real-time tracking, and proper hand-over to a secondary steering device are essential. Various user localization techniques have been reported for optical-wireless communication $[5,6]$. However, none of these techniques tackled the issues of precise real-time user tracking and hand-over needed in steered IOWC, where line-of-sight (LoS) blocking is a major issue. In this paper, we demonstrate a narrow beam based IOWC system with real-time user tracking and proper hand-over in order to support continuously moving users. These functionalities are enabled by image processing where the user plane is captured by low-cost cameras installed together with the beam steering devices. It is demonstrated here that connection to a secondary beam steering device can be established within $40 \mathrm{~ms}$ when there is LoS blocking from the beam steerer currently serving the user. Moreover, by anticipating where the user could be at any time, change of the steering direction, or proper hand-over to another steering device can be performed without significant delay (signal drop) in the wireless signal.

\section{Indoor infrared OWC demonstration}

Our indoor beam-steered demonstrator system is depicted in Fig. 1. Pencil-beam radiating antennas (PRAs) which each can steer multiple optical pencil beams into directions determined by the wavelengths of the signals are installed at the ceiling of each room. These PRAs are fully passive, and are constructed by means of arrayed waveguide grating routers (AWGRs) with high number of output ports. The output ports are then arranged in a 2D fibre array and put in front of a camera lens. The defocussing technique described in [7] allows us to provide improved coverage at any freespace distance. With this design, femto-cells of diameter $\sim 10 \mathrm{~cm}$ have been formed at a free-space distance of $\sim 2 \mathrm{~m}$, each addressed by a specific wavelength. A central communication controller at the residential gateway takes care of the dynamic routing of signals to where they are needed using tunable transmitters. In order to determine the accurate position of the users for the beam steering, localization of the user devices using a passive retroreflecter (a retroreflector reflects light rays to where they came from) was demonstrated in our previous work [8]. The localization process starts with scanning the coverage area by sweeping the wavelength of an IR beam by means of a tunable laser diode. When the localization processor at the central site detects a reflected signal (from the user equipped with a retroreflector), it stops and stores the current wavelength of the tunable laser. This way the device is located precisely and without requiring any active component at the user terminal. Though this novel technique is simple and energy efficient, it is not possible to track the user device in real-time given the presently used laser tuning control.

In order to support user mobility, real-time user tracking is essential, whether to anticipate the movement and 
estimate the wavelength and PRA needed to serve the user at any time or to provide proper hand-over to a secondary PRA in case of LoS blocking. Hence, in our demonstrator system we included a low-cost optical camera (placed near one of the PRAs, as shown in Fig. 1) [9]. The user's receiving component is surrounded with infrared light-emitting-diode (LED) markers in order to notify the camera of its presence. The spacing between the LED markers is designed so that they are easily distinguishable from each other at a free-space distance of up to $\sim 5 \mathrm{~m}$. Increasing the number of LEDs will help to increase the accuracy of the localization, however it also increases the user device's power consumption. By visualizing the $\mathrm{x}$ - and $y$ - coordinates of the LEDs, and then calculating the central point of the shape created by directly connecting the LEDs, the location of the receiver is estimated in the image plane which can easily be translated to its actual location [9]. We have developed an image processing algorithm to achieve this. After the user plane is captured by the camera, the image is converted to grayscale and filtered with adaptive thresholding to black (with a value of 0 ) and white (with a value of 255); the bright LEDs appear as white pixel areas in the image frame while the rest of the image appears black (see Fig. 3a). The location information is translated to the cell number, and since the correspondence between cell and wavelength is already stored in

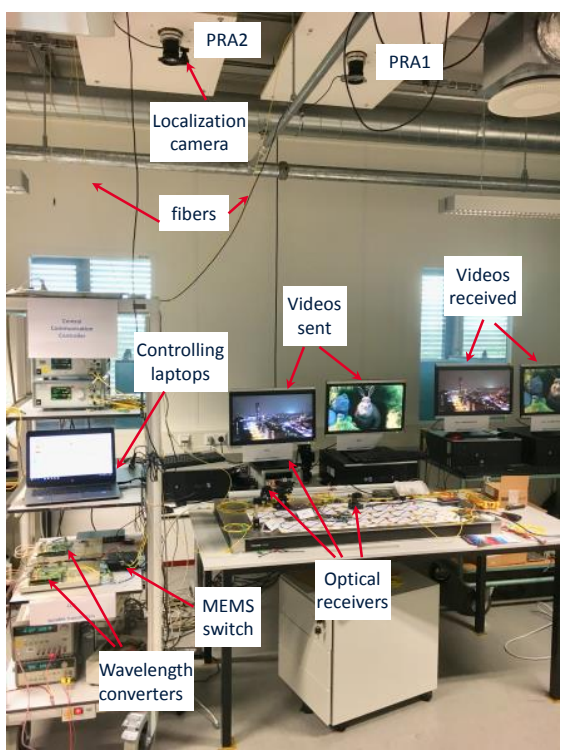

Fig. 1. Indoor optical-wireless communication demonstrator including real-time user tracking a table, the connection can be setup with the appropriate wavelength. The speed at which the user can be tracked depends on the frame rate of the camera used and the video signal processing time.

\section{Experimental demonstration and results}

The demonstrator setup as detailed in Fig. 2a is used to show the realtime tracking and handover concept. The two PRAs are separated by a distance of $\sim 80 \mathrm{~cm}$. Previously, we have demonstrated an optical-wireless data transmission speed of $112 \mathrm{~Gb} / \mathrm{s}$ using PAM-4 [7]. Each PRA has a coverage angle of $\sim 30^{\circ} \times 30^{\circ}$ which corresponds to a $1.1 \mathrm{~m} \times 1.1 \mathrm{~m}$ coverage area at a free-space distance of $\sim 2 \mathrm{~m}$. The separation between the two PRAs was designed in such a way that there will be an overlap region. This allows us to tackle LoS blocking to the current PRA by switching to the second PRA (see Fig. 2a). With a resolution of $1280 \times 720$, the camera provides a coverage area of $>2.4 \mathrm{~m} \times 1.5 \mathrm{~m}$ at a freespace distance of $\sim 2 \mathrm{~m}$ with a frame rate of $100 \mathrm{fps}$, which encompasses the area covered by the two PRAs, which is $\sim 2 \mathrm{~m} \times 1 \mathrm{~m}$. The image from the camera is processed in a Raspberry Pi 3 controller which communicates with the central processor via a WiFi connection. A MEMS based optical cross connect (OXC) is implemented at the RG in order to dynamically route the optical-wireless signal to the appropriate PRA when the user moves, and share the tunable lasers located at the RG among multiple users. The entire network is orchestrated at the central controller using LABVIEW. At the receiver side, because of yet unavailable optical-wireless receiver with wide FoV and wide bandwidth, we used a receiver with $150 \mathrm{MHz}$ bandwidth. The FoV achieved using this receiver was $\sim 10^{\circ}$. Although the binary data transmission speed obtained using this receiver was $\sim 380 \mathrm{Mb} / \mathrm{s}$ (see eye diagrams in Fig. 3c), it can still be deployed to provide data transmission of $>600 \mathrm{Mb} / \mathrm{s}$ per user using PAM-4. In order to demonstrate handover to the second PRA, we used an optical sensing PD with an aperture of $5 \mathrm{~mm}$. We are currently working on optical-wireless receivers with wide FoV that allow $\mathrm{Gb} / \mathrm{s}$ transmission speeds using binary modulation formats such as OOK.

Three LED markers with diameter $2.8 \mathrm{~mm}$ and spacing $2.5 \mathrm{~cm}$ are placed around this receiver as shown in Fig. $2 \mathrm{~b}$
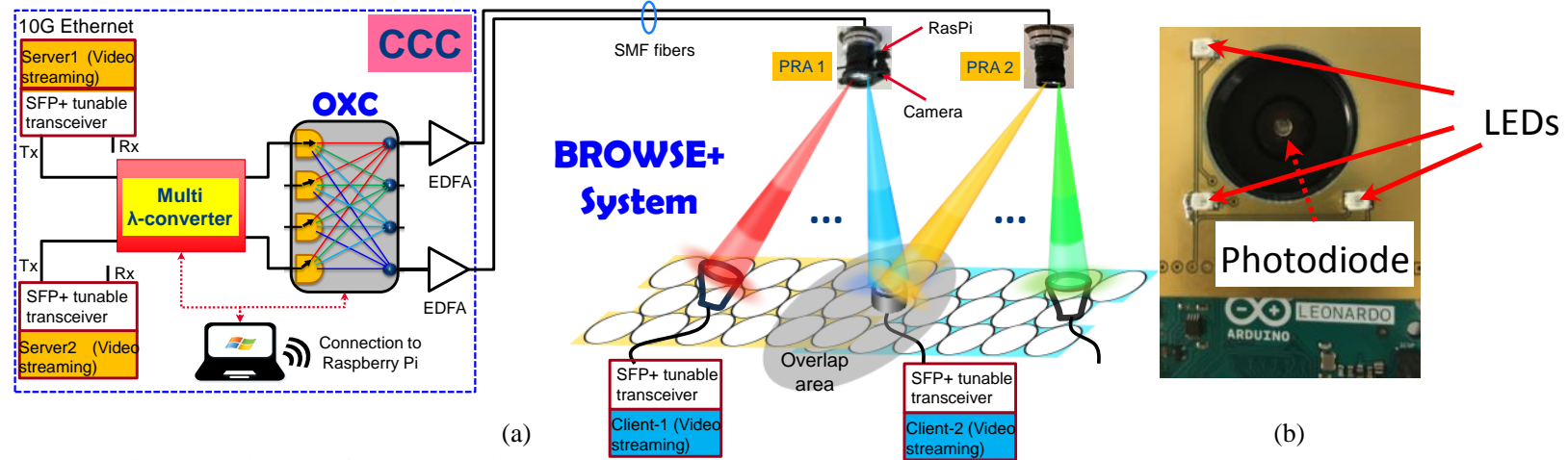

Fig. 2. (a) Diagram of the optical-wireless demonstration system; (a) Top view of the wireless receiver with surrounding LEDs 


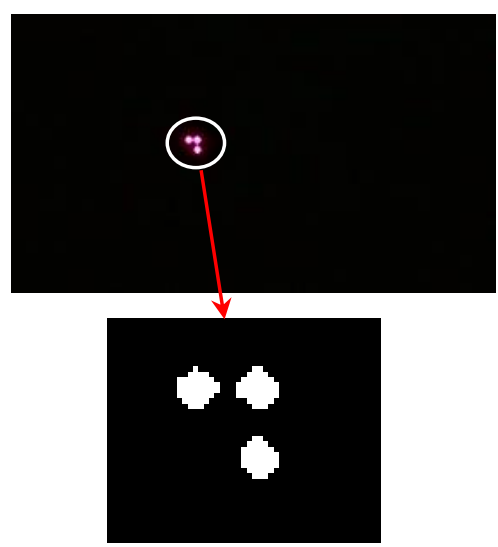

(a)

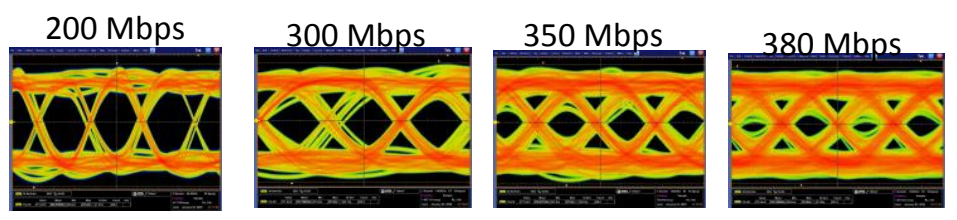

(b)

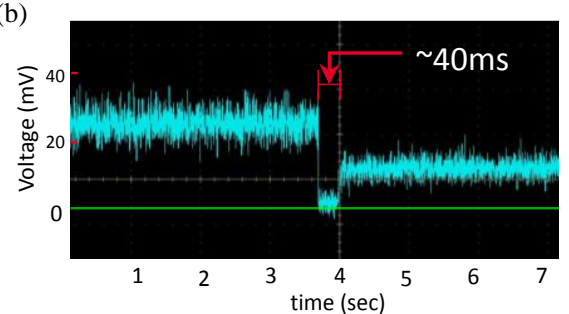

(d)

Fig. 3. (a) Captured image where the coverage area appears black, except when there is a user with infrared LEDs (inset: the user image after thresholding); (b) Different eye diagrams captured by a 150MHz receiver; (c) Real-time user tracking at a speed lower than the camera frame rate.; (d), Delay of handover to a secondary PRA during LoS blocking.

for the localization and tracking. Fig. 3a shows the captured image by the camera at the start of the communication. The individual LEDs are clearly visible on the image which can then be processed to determine the location of the user. The communication is started with the appropriate wavelength obtained from a table that contains the a priori stored calibrated cell vs wavelength information. Note that the camera captures an image of the user plane at a rate of $100 \mathrm{fps}$, and the image is processed within this $10 \mathrm{~ms}$. Hence, when the user starts moving, the camera can track its movement in real-time (the central controller knows its location at all times; its position is updated every 10ms). When the user enters into another cell the wavelength has to be changed to the one corresponding to the new cell. Since all this information is automated using LABVIEW, the total time needed to establish this new connection (or the signal delay/drop) is mainly limited by the laser tuning process using Arduino, and it is $\leq 10 \mathrm{~ms}$ as shown in Fig. $3 \mathrm{~b}$ (note that the user is moving continuously). If the user is in the overlap region as shown in Fig. 2a, we can also circumvent LoS blocking. When the camera captures the image of the user plane the user's location is determined with respect to the two PRAs. Hence, when the communication link is blocked, the controller immediately switches to the second PRA (a.k.a. handover) to return the connection with a new wavelength. In this case the total time taken to re-establish the communication link is also affected by the switching time (each PRA is connected to an output port of the MEMS switch), in addition to the laser tuning process. This time is $\sim 40 \mathrm{~ms}$ as shown in Fig. 3d. Note that the received power may fluctuate a little at different locations, and when using different PRAs due to the limited FoV of the receiver.

\section{Conclusion}

We demonstrated a real-time user tracking and handover mechanism for high-speed indoor beam-steered optical wireless system using accurate user localization and tracking by deploying a low-cost camera (near IR range). Although we used a lower speed optical-wireless receiver (which is capable of receiving $400 \mathrm{Mb} / \mathrm{s}$ OOK signal) because of its wide FoV, the mechanism is applicable to $\mathrm{Gb} / \mathrm{s}$ transmission speeds using a receiver with larger bandwidth and wide FoV, which we are working on currently.

This work is funded by the ERC-FP7 PoC project BROWSE-PLUS and the TU/e-KPN flagship SMART-One program.

\section{References}

1. H. Haas., L.Yin, Y. Wang, C. Chen, "What is LiFi?," J. Lightw. Technol., 34, 6 (2016), p. 1533.

2. A. Gomez, K. Shi, C. Quintana, M. Sato, G. Faulkner,B. B. Thomsen, D. C. Brien, "Beyond 100-Gb/s indoor wide field-of-view optical wireless communications,” IEEE Photonics Technol. Lett., 27, 4 (2015), p. 367.

3. T. Koonen, J. Oh, K. Mekonnen, Z. Cao, and E. Tangdiongga, "Ultra-high capacity indoor optical wireless communication using 2D-steered pencil beams," J. Lightw. Technol. 34, 20 (2016), p. 4802.

4. https://en.wikipedia.org/wiki/Laser_safety.

5. T. H. Do and M. Yoo, "An in-depth survey of visible light communication based positioning systems," Sensors, 16, 5 (2016), Paper no. 678.

6. A. Gomez, K. Shi, C. Quintana, G. Faulkner, B. C. Thomsen, and D. C. O'Brien, "A 50 Gb/s transparent indoor optical wireless communications link with an integrated localization and tracking system," J. Lightw. Technol., 34,10 (2016), p. 2510.

7. A.M.J. Koonen, F. Gomez-Agis, F.M. Huijskens, K. A. Mekonnen, "High-Capacity Optical Wireless Communication Using TwoDimensional IR Beam Steering," J. Lightw. Technol., 36, 19 (2018), p. 4486.

8. T. Koonen, K. Mekonnen1, F. Huijskens, E. Tangdiongga, "Fully Passive User Localisation for Beam-Steered High-Capacity Optical Wireless Communication System,” ECOC (2019).

9. N.Q. Pham, K.A. Mekonnen, E.Tangdiongga, A. Mefleh, A.M.J. Koonen, “Accurate indoor localisation for beam-steered OWC system using optical camera," in ECOC (2019). 